\title{
OBITUARY
}

\section{ARTHUR TUDOR EDWARDS}

It is an irony of fate that the first obituary notice in this new journal should be that of Tudor Edwards, to whose persistent advocacy the journal largely owes its existence.

Arthur Tudor Edwards was born in 1890 and was educated at Mill Hill, Cambridge, and the Middlesex Hospital, where he qualified in 1913. Here in the old hospital before the rebuilding he received his early surgical teaching from Sir John Bland-Sutton and Mr. (now Sir Gordon) Gordon-Taylor, and here he was in turn house-surgeon and surgical registrar. Then the first World War gave him that confidence and success of technique which stood him in such good stead in his later pioneer work - at Wimereux under Sinclair, at Barlin under Cuthbert Wallace, and, in an aftermath of the battlefields, at Leeds under Littlewood. The gods gave him good teachers, and the casualties of a crippling war extensive experience. On returning to civilian life he joined the staffs of the Westminster and the Queen Mary's Hospital, Roehampton. Then in 1921 he was appointed to Brompton, and was obviously cast for the part of a pioneer chest surgeon. Before the war there had been straws in the wind indicating a new approach to thoracic diseases. Artificial pneumothorax had achieved some notable successes and had set men thinking about other means of collapsing the lung. Furthermore the technique had shown that the healthy pleura was not inviolate. The advances came first in tuberculosis. In malignant disease as late as 1925 no less an authority than Lilienthal described an operation for curetting in a sentence which now sounds positively shattering. "The tumour," he says, "is incised and a large curette is used to scoop or ream out portions of the neoplasm " before radiation. And in the same year the Sauerbruch Clinic had only five radical operations to its credit. It was into this terra incognita, therefore, that Tudor Edwards and a small band of pioneer surgeons in the country entered. In 1927 he published an account of seven operations for intrathoracic new growths, in one of which he had used a combination of a diagnostic artificial pneumothorax and thoracoscopy for the first time in this country, and in another had performed a lobectomy; whilst in the same year he recorded 41 thoracoplasties with an operative mortality of 7.3 per cent and with 52.4 per cent of his cases cured or much improved. Later he was the first surgeon in this country to perform lobectomy by dissection in place of the earlier tourniquet method, and the first also to do pneumonectomy. His record closes with an analysis of over a thousand cases of bronchial carcinoma, in 70 of which resection of the lung was performed, published in the first number of this journal in March of this year. 


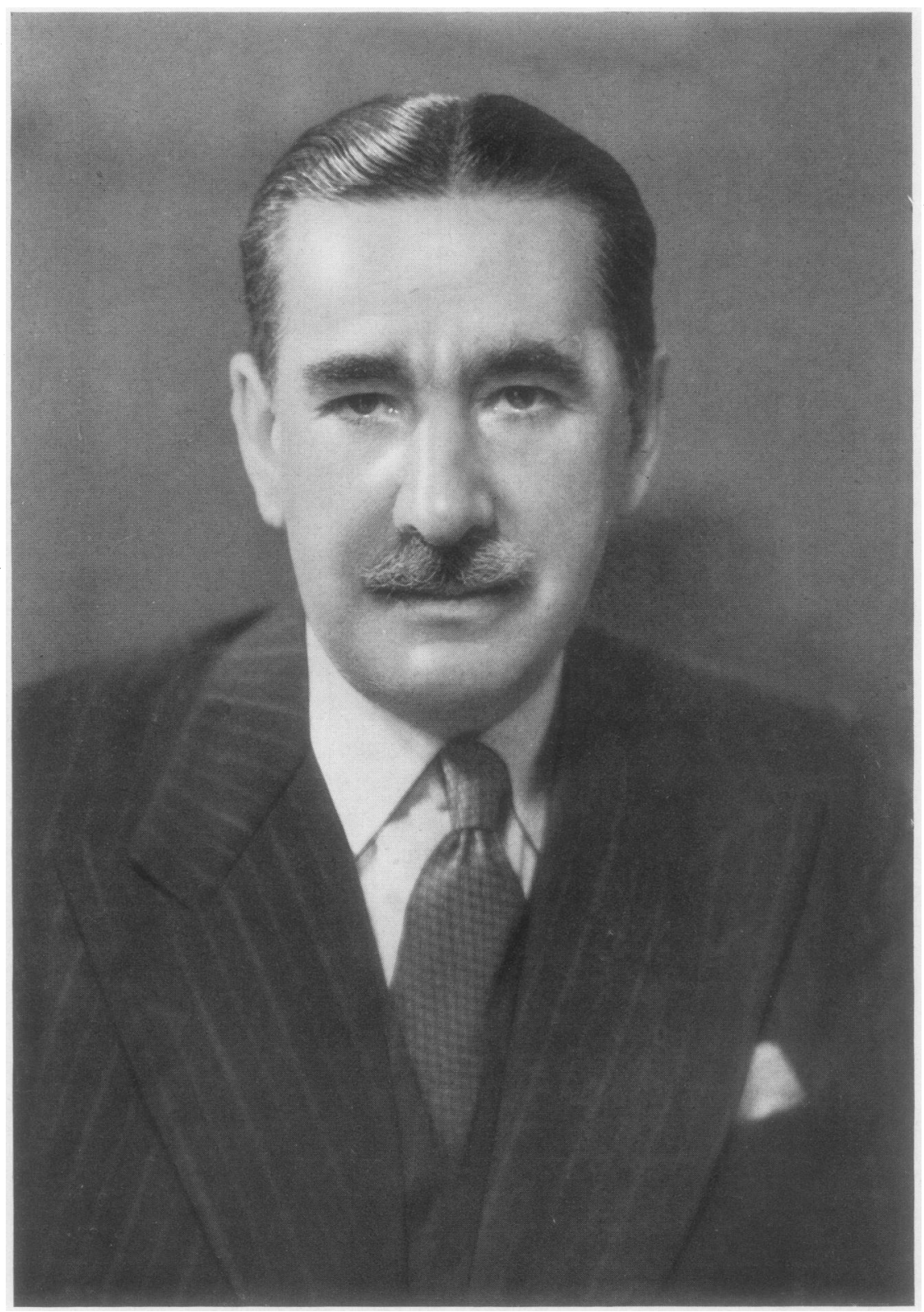

ARTHUR TUDOR EDWARDS, M.D., M.Chir., F.R.C.S. 
Eventually he decided to give up general surgery, and he resigned from the Westminster Hospital to take charge of the new department of thoracic surgery at the London Hospital. He also became consulting thoracic surgeon to the L.C.C., to King Edward VII Sanatorium, Midhurst, and to Queen Alexandra's Hospital, Millbank, combining all this work with an extensive consulting practice involving heavy responsibilities for major thoracic operations. These were years of great strain, and a breakdown in health in 1938 was the inevitable result. Another breakdown followed a year later, but his determination drove him on and the second World War found him amongst the elder statesmen of British surgery, acting as consulting thoracic surgeon and adviser to the War Office, the Royal Air Force, and the Ministry of Health. During the war years he devoted much of his precious time to Midhurst, and especially to the R.A.F. block there. He found time, too, for the Council of the Royal College of Surgeons and for the presidencies of the Association of Thoracic Surgeons and the newly founded Association for the Study of Diseases of the Chest. Indeed it is doubtful if the latter Society could have come into being at all during war-time without his help. These war years, too, brought him honorary degrees from Grenoble and Oslo. Then, in the summer of this year, the end came. He broke down soon after returning from presiding at the Annual Meeting of the Association for the Study of Diseases of the Chest, at Liverpool, and died on holiday, almost literally in harness as he would probably have wished to do.

It is not given to most men to see their speciality reach maturity during their lifetime. This was the experience of Tudor Edwards, and he was an integral part of the achievement. He was possessed of a firm determination, great courage, and a tenacity of purpose which enabled him to go through with the pioneer work of thoracic surgery in the face of much conservatism and opposition in the earlier stages. There was no place in his scheme of things for the decorative impressionalist. Nothing but the best would satisfy him, and if he expected this high standard in others he exacted it no less from himself. Jan van Eyck used to sign his pictures with the words "Als Ich Kann." This same spirit of doing everything to the best of his ability imbued Tudor Edwards to the last, and we his friends mourn the death, in the maturity of his powers, of a truly great colleague.

S. R. G. 